\title{
FORMULASI MASKER GEL (PEEL OFF MASK) SARI BUAH TOMAT APEL (Licopersicum esculentum Mill)
}

\author{
Faradiba *), Ermina Pakki ${ }^{* *)}$, Auliawati Rusli ${ }^{*}$, Amelia Jabbar *) \\ ${ }^{*}$ Fakultas Farmasi Universitas Muslim Indonesia \\ ${ }^{* *)}$ Fakultas Farmasi Universitas Hasanuddin \\ Email : faradiba76@yahoo.com
}

\begin{abstract}
In this study, three formulas gel with varying polyvinyl alcohol 9\%, 9,5\%, and $10 \%$. Then do the evaluation of physical stability by organoleptic examination of the test parameters, measurements of viscosity, yield value determination and $\mathrm{pH}$ determination before and after accelarated storage. The results obtained in the second organoleptic examination of the gel formula does not change the color, smeel and consistency before and after accelerated storage. In the viscosity measurements obtained results in the formula $A$ were not significantly different before and after accelerated storage. Results of statistical analysis of the value of yield showed that the formula $A$ were not significantly different before and accelerated storage. In rheogram formula $A$ have the curves that coincide, formula $B$ and $C$ have seen that the curve is not too close together before and after accelerated storage. In $\mathrm{pH}$ determination, formula $\mathrm{A}$ have neutral $\mathrm{pH}$ of 6,9 , formula $B$ and $C$ have $\mathrm{pH}$ of 6,8 , so it can be concluted that two stocks is stable, but their stability is the most optimal formula $A$ (concentration $9 \%$ ).
\end{abstract}

Key words : Mask Gel, Apple Tomato

\section{PENDAHULUAN}

Vitamin A, Vitamin C terdapat dalam buah-buahan dan sayursayuran seperti tomat, dapat memberikan nutrisi yang dibutuhkan kulit dan mengangkat sel-sel kulit mati sehingga dapat menjaga kesehatan kulit. Selain itu dalam pigmen merah tomat banyak mengandung lykopen yang dapati mencerahan kulit (Iwanudin, 2007). Berdasarkan khasiat yang terdapat pada tomat varietas apel (Lycopersicum esculentum Mill pyriforme) dapat berpotensi untuk dikembangkan menjadi suatu sediaan kosmetik yaitu masker Peel off.

Masker Peel off merupakan masker yang praktis, setelah kering masker tersebut dapat langsung diangkat tanpa perlu dibilas (biasa dikenal dengan sebutan masker peel off).Selain itu efek dari zat aktif pada masker dapat lebih lama berinteraksi dengan kulit wajah. Manfaat masker 
gel antara lain dapat mengangkat sel kulit mati agar kulit bersih dan segar. Masker ini juga dapat mengembalikan kesegaran dan kelembutan kulit, bahkan dengan pemakaian teratur dapat mengurangi kerutan halus pada kulit wajah (Balsam, 1975)

Bahan-bahan pembentuk gel yang biasa digunakan salah satunya polivinil alkohol. Polivinil alkohol digunakan untuk bahan pembentuk gel yang cepat kering, memberikan hasil lapisan yang kuat dan plastik, memberikan kontak yang baik dan pengobatan yang memberikan perlindungan pada kulit dengan tampilan yang baik (Cooper and Gunns, 1979).

Dari uraian di atas maka akan dilakukan penelitian formulasi sari buah tomat varietas apel (Lycopersicum esculentum Mill pyriforme) sebagai masker Peel off dengan variasi konsentrasi polivinil alkohol. Tujuan penelitian ini untuk menentukan sediaan masker Peel off tomat varietas apel (Lycopersicum esculentum Mill pyriforme) yang paling stabil.

\section{METODE PENELITIAN}

\section{A. Alat yang Digunakan}

Alat yang digunakan yaitu cawan porselin, gelas piala 50 dan $100 \mathrm{ml}$ (Pyrex),freeze dry, gelas ukur 25 dan 50 ml (Iwaki,pyrex), lemari pendingin (Sanken), stamper dan mortir, timbangan analitik (Chyo), thermometer, viskometer RVT (Brookfield).

\section{B. Bahan yang Digunakan}

Air suling, alkohol 70\%, tomat varietas apel (Lycopersicum esculentum Mill pyriforme), metil paraben, minyak mawar, natrium bisulfit, propilenglikol, dan polivinil alkohol.

\section{Formulasi Sediaan Gel}

Formulasi masker Peel off dari sari buah tomat varietas apel (Lycopersicum esculentum Mill pyriforme) dengan menggunakan bahan dasar pembentuk gel polivinil alkohol dengan variasi konsentrasi $9 \%, 9,5 \%$ dan $10 \%$ dengan zat tambahan air suling, alkohol $70 \%$, metil paraben, minyak mawar, natrium bisulfat, propilenglikol.

\section{Pembuatan Masker Peel Off}

a. Formula gel sari tomat varietas apel (Lycopersicum esculentum Mill pyriforme) dengan basis polyvinyl alkohol konsentrasi $9 \%$.

Gel dibuat dengan cara mendispersikan polyvinyl alkohol dalam aqudest yang telah dipanaskan hingga suhu 
$70{ }^{\circ} \mathrm{C}$, dimasukkan ke dalam lumpang kemudian digerus hingga terbentuk dispersi yang jernih. Kemudian ditambahkan propilenglikol, metil paraben dan natrium bisulfit hingga terbentuk gel yang mengembang dan jernih. Kedalam basis ditambahkan ekstrak sari tomat (Lycopersicum esculentum Mill pyriforme) yang dilarutkan dalam alkohol. Setelah itu sediakan dan minyak mawar, pengadukan dihentikan dan gel disimpan dalam wadah tertutup. Gel didiamkan selama 24 jam hingga gelembung hilang, kemudian dilakukan pengukuran $\mathrm{pH}$ dan viskositas gel.

b. Pembuatan masker Peel off dengan polyvinyl alkohol konsentrasi $9,5 \%$ dan $10 \%$ seperti cara kerja di atas.

\section{E. Evaluasi kestabilan dengan} kondisi dipercepat (Aulton, 1988 dan Benker, 1995).

Evaluasi kestabilan sediaan gel dilakukan sebelum dan sesudah kondisi dipaksakan.
Kondisi dipaksakan dilakukan dengan menyimpan sediaan gel pada tempetatur $5^{\circ} \mathrm{C}$ dan $35^{\circ} \mathrm{C}$ secara bergantian masing-masing 12 jam selama 10 siklus.Parameter Evaluasi sebagai berikut :

a. Pemeriksaan organoleptis Pemeriksaan organoleptis meliputi perubahan warna, konsistensi dan bau sediaan.

b. Uji viskositas dan penentuan aliran

Sebanyak $100 \quad \mathrm{ml}$ sediaan gel dimasukkan ke dalam gelas kimia kemudian diukur viskositasnya menggunakan viskometer (Brookfield).

C. $\mathrm{pH}$

Pengukuran viskositas sediaan masker Peel off sari buah tomat vaietas apel dilakukan dengan mengunakan alat ukur $\mathrm{pH}$ salah satunya $\mathrm{pH}$ meter atau kertas $\mathrm{pH}$ universal.

\section{HASIL PENELITIAN}

Pembuatan gel dengan variasi konsentrasi polivinil alkohol sebagai bahan pembentuk gel memberikan hasil sebagai berikut : 
1. Pengamatan organoleptis

\begin{tabular}{|c|c|c|c|}
\hline \multirow{2}{*}{ Formula } & \multirow{2}{*}{ Jenis Pemeriksaan } & \multicolumn{2}{|c|}{ Kondisi } \\
\hline & & Sebelum & Sesudah \\
\hline \multirow{3}{*}{ Formula A } & Bau & Khas aromatis & Khas aromatis \\
\hline & Warna & Jingga & Jingga \\
\hline & Konsistensi & kental & kental \\
\hline \multirow{3}{*}{ Formula B } & $\mathrm{Bau}$ & Khas aromatis & Khas aromatis \\
\hline & Warna & Jingga & Jingga \\
\hline & Konsistensi & kental & kental \\
\hline \multirow[b]{2}{*}{ Formula C } & $\mathrm{Bau}$ & Khas aromatis & Khas aromatis \\
\hline & $\begin{array}{l}\text { Warna } \\
\text { Koncictenci }\end{array}$ & Jingga & Jingga \\
\hline
\end{tabular}

\section{Keterangan :}

$\mathrm{A} \quad=$ Masker Peel off dengan polivinil alkohol $9 \%$

$\mathrm{B}=$ Masker Peel off dengan polivinil alkohol 9,5\%

C = masker Peel off dengan polivinil alkohol $10 \%$

2. Pengukuran Viskositas dan Penentuan Tipe Aliran

\begin{tabular}{cccc}
\hline Kondisi & Formula A & Formula B & Formula C \\
\hline Sebelum & 48,43 & 146,43 & 185,63 \\
Sesudah & 50,06 & 155,00 & 193,30 \\
\hline
\end{tabular}

Sedangkan tipe aliran yang terbentuk ialah plastis yang memiliki nilai yield rata-rata (dyne $/ \mathrm{cm}^{2}$ ) sediaan masker Peel off tomat sebelum dan sesudah penyimpanan dipercepat yaitu :

\begin{tabular}{cccc}
\hline Kondisi & Formula A & Formula B & Formula C \\
\hline Sebelum & 1,569 & 3,07 & 2,29 \\
Sesudah & 2,283 & 7,53 & 6,64 \\
\hline
\end{tabular}

\section{Pengujian $\mathrm{pH}$ sediaan}

Sediaan masker peel off sari buah tomat (Lycopersicum esculemntum Mill pyriforme) mempunyai $\mathrm{pH}$ yaitu formula $\mathrm{A}$ memiliki $\mathrm{pH}$ 6,9,formula $\mathrm{B}$ dan $\mathrm{C}$ memiliki pH 6,8 . Hal ini berdasarkan pengukuran $\mathrm{pH}$ dengan menggunakan $\mathrm{pH}$ meter.

\section{PEMBAHASAN}

Formulasi Masker gel peel off sari buah tomat apel ditambahkan alkohol yang berfungsi sebagai bahan untuk mempercepat waktu pengeringan atau penguapan. Propilenglikol merupakan bahan yang berfungsi sebagai humektan yaitu mencegah kekeringan pada sediaan utamanya pada wadah.Selain itu propileglikol juga berfungsi sebagai emolien sehingga pada saat masker Peel off diangkat atau dilepas dari kulit wajah tidak menyebabkan rasa sakit.

Natrium bisulfit digunakan sebagai antioksidan untuk melindungi tomat dari oksidasi.Penambahan metil 
paraben dimaksudkan sebagai pengawet. Sedangkan propilenglikol pada formula ini digunakan sebagai humektan.Penambahan minyak mawar berfungsi sebagai pengharum atau pewangi agar sediaan lebih menarik.

\section{Pengamatan Organoleptis}

Pengamatan organoleptis dilakukan untuk mengetahui ada tidaknya perubahan warna dan bau yang terjadi selama kondisi dipaksakan.

Berdasarkan pengamatan organoleptis ini, ketiga sediaan masker yang dihasilkan tidak mengalami perubahan warna dan bau baik sebelum dan sesudah kondisi dipaksakan.

\section{Viskositas}

Analisa statistik untuk pengukuran viskositas menunjukkan hasil yang sangat signifikan yang kemudian dilakukan uji lanjutan dengan metode BNJ (Beda Nyata Jujur) kemudian diperoleh Hasil formula A sebelum dan sesudah kondisi dipaksakan menunjukkan hasil yang non signifikan sedangkan untuk formula B dan C pada sebelum dan sesudah kondisi dipaksakan menunjukkan hasil yang sangat signifikan.

\section{Nilai Yield}

Sediaan masker peel off Tomat varietas apel menunjukkan tipe aliran Non-Newton yaitu plastissesuai yang tergambar pada grafik rheogram, dimana semua kurva formula tidak dapat melalui sumbu tekanan geser dan ketiganya memiliki nilai yeald, dimana nilai yield adalah besarnya gaya atau tekanan geser yang harus dilampaui agar suatu sistem dapat mengalir. Nilai yield dan viskositas saling berhubungan karena semakin tinggi viskositas, maka nilai yeald semakin besar. Dari hasil penentuan nilai yield pada ketiga formula terjadi perubahan antara sebelum dan sesudah penyimpanan dipercepat yaitu pada formula $A$ menunjukkan hasil yang Non signifikan sedangkan pada formula $B$ dan $C$ menunjukkan sangat signifikan.

\section{Gambar Rheogram}

Pada gambar rheogram terlihat bahwa formula $A$ sebelum dan sesudah kondisi dipaksakan memiliki kurva yang berimpit, formula B dan C sebelum dan sesudah kondisi dipaksakan memiliki kurva yang hampir berimpit. 
Dari hasil diatas dapat disimpulkan bahwa sediaan masker gel dari ketiga formula tersebut yaitu formula $A$ (konsentrasi 9\%), formula $B$ (konsentrasi 9,5\%) dan formula C (konsentrasi 10\%) memiliki kestabilan yang baik namun yang memberikan kestabilan optimum yaitu formula A (konsentrasi 9\%), karena tidak mengalami perubahan fisis antara sebelum dan sesudah penyimpanan.

\section{KESIMPULAN}

Berdasarkan hasil penelitian, Masker Peel off sari buah tomat varietas apel (Lycopersicum esculentum Mill pyriforme) Formula A yang menggunakan polivinyl alkohol dengan konsentrasi 9\% memiliki kestabilan fisis optimal.

\section{DAFTAR PUSTAKA}

Aulton, M. E., 1988, Pharmaceutics : The Science of Dosage Form design, Churchill liviningstone, New York.

Balsam, M. S., saragin, E., 1975, Cosmetics Science and Technology, Volume I, second Edition, Wiley Interscience, New York, London-SydneyToronto.

Banker, G. S., and Rhodest, C. T., 1990, Modern Pharmaceutics, Second Edition Revised and Expanded, Marcel dekker. Inc, New York-Basel.
Basuki. S. Kinkin., 2003. Tampil Cantik dengan Perawatan Sendiri. Gramedia Pustaka Utama, Jakarta.

Cooper and Gunns., 1979. Dispensing for Pharmaceutical Students.Twelfth Edition. Pitman Medical, London.

Dalimartha, S., 1998. Atlas Tanaman Obat Indonesia, Jilid I, Trubus Angriwidya, Jakarta.

Ditjen POM, 1979, Farmakope Indonesia, edisi ketiga, Departemen Kesehatan Republik Indonesia, Jakarta.

Gennaro, A. R., 1990, Remington's Pharmaceutical Science, $18^{\text {th }}$ Edition, Mack Publishing Company, Easton, pennsylvania.

Iwanudin. 2007. "Khasiat dan Manfaat Tomat", (http://mumtazanas.wordpress. com, diakses 8 Maret 2010)

Kibbe, A, H., 2000, Handbook of Pharmaceutics Excipient $3^{\text {th }}$, American Pharmaceutical Press, Washington Dc.

Lachman, L., Lieberman, H, A., and kanig, J. L., 1986, Terjemahan Teori dan Praktek Farmasi Industri, Oleh Siti Suyatmi, 1994, j UI-Press, jakarta.

Martin, E, L., 1971, Dispensing of Medication, mack Publishing Company, easton pennsylvania.

Parrot, E, L., 1971, Pharmaceutical Technology Fundamental Pharmaceutics, the third Revision, Burgess Publishing Company, Minneapois. 
Supriati, Y \& Siregar, F. D. 2009. "Bertanam Tomat dalam Pot dan Polibag", Penebar Swadaya: Jakarta

Tranggono.J.R. 2007.Pegangan IImu Pengetahuan Kosmetik. Penerbit PT. Gramedia Pustaka Utama, Jakarta.

Wasitaatmadja, S.M. 1989. Penuntun IImu Kosmetik Medik,
Universitas Indonesia, Jakarta.

Wiryanto, B. T. W. 2002. "Bertanam Tomat", Penerbit Agromedia Pustaka: Jakarta. (http/:garnier/skincare.com),(h ttp://warnadunia.com/khasiatkandungan-dan-manfaattomat-sumber-antioksidanalami/asih baru). 